Hydrology and Earth System Sciences, 8(4), 813-822 (2004) (C) EGU

\title{
Quantification of nitrate leaching from forest soils on a national scale in The Netherlands
}

\author{
J. Kros ${ }^{1}$, A. Tietema², J.P. Mol-Dijkstra ${ }^{1}$ and W. de Vries ${ }^{1}$ \\ ${ }^{1}$ Alterra, Green World Research, Wageningen University and Research Centre, PO box 47, NL 6700 AA Wageningen \\ ${ }^{2}$ University of Amsterdam, Netherlands Centre for Geo-Ecological Research, Nieuwe Prinsengracht 130, NL 1018 VZ Amsterdam
}

Email for corresponding author: Hans.Kros@wur.nl

\begin{abstract}
To evaluate the effects of nitrogen $(\mathrm{N})$ emission policies, reliable information on nitrate concentrations and leaching fluxes from forest ecosystems is necessary. Insight into the regional variability of nitrate concentrations, to support local policy on emission abatement strategies is especially desirable. In this paper, three methods for the calculation of a spatial distribution of soil nitrate concentrations in Dutch forest ecosystems are compared. These are (i) a regression model based on observed nitrate concentrations and additional data on explanatory variables such as soil type, tree species and nitrogen deposition (ii) a semi-empirical dynamic model WANDA, and (iii) a process-oriented dynamic model SMART2. These two dynamic models are frequently used to evaluate the effects of reductions in nitrogen deposition at scales ranging from regional to countrywide. The results of the regression model evaluated the performance of the two dynamic models. Furthermore, the results of the three methods are compared with the steady-state approach currently used for the derivation of nitrogen critical loads. Both dynamic models, in the form of cumulative distribution functions, give similar results on a national scale. Regional variability is predicted differently by both models. Discrepancies are caused mainly by a difference in handling forest filtering and denitrification. All three methods show that, despite the high nitrogen inputs, Dutch forests still accumulate more $\mathrm{N}$ than they release. This implies that, in respect of groundwater quality, presently acceptable nitrogen deposition is higher than the (long-term) critical loads. However, in areas with high atmospheric nitrogen input, all three methods indicate that the EU standard for nitrate in groundwater $\left(50 \mathrm{mg} \mathrm{NO} \mathrm{l}^{-1}\right)$ is exceeded. Steady-state with nitrogen deposition seems to have been reached in about $10 \%$ of the forested area, with a nitrate concentration greater than $50 \mathrm{mg} \mathrm{NO}_{3} \mathrm{l}^{-1}$.
\end{abstract}

Keywords: soil modelling, up-scaling, model validation, critical load

\section{Introduction}

In large parts of western Europe, in The Netherlands in particular, nitrogen $(\mathrm{N})$ input from atmospheric deposition to forest ecosystems exceeds the long-term capacity of the ecosystem to retain N (De Vries et al., 1995a; Gundersen, 1995; Dise et al., 1998). This may have several adverse effects: (i) decrease in botanical diversity (Bobbink et al., 1998), (ii) eutrophication of ground and surface waters (De Vries, 1994), (iii) acidification (Van Breemen et al., 1982) and (iv) decreased tree vitality (Boxman and van Dijk, 1988). For decades, government authorities developed policies and measurements aimed at reducing $\mathrm{N}$ inputs to semi-natural ecosystems. Notable examples are the $\mathrm{NO}_{\mathrm{x}}$ protocol (Sophia protocol, UN/ECE, effective from 1994) and the multi-pollutant-multi-effect protocol (Gothenburg protocol, UN/ECE, effective from 1999). To evaluate $\mathrm{N}$ emission policy it is desirable to have at an appropriate spatial scale, ranging from regional to national or even European scale, a reliable map of the $\mathrm{NO}_{3}$ concentration in drainage water and $\mathrm{N}$ leaching fluxes from semi-natural ecosystems.

Various methodologies are available for the quantification of the extent and geographical distribution of $\mathrm{N}$ leaching. They range from statistical methods based directly on measurements, such as multiple regression (Leeters et al., 1994), generalised additive modelling (Tiktak et al., 1998, though this refers to cadmium leaching), stratified blockKriging (Pebesma and de Kwaadsteniet, 1997) and process- 
oriented models ranging from simple (De Vries et al., 1989, 1995b) to complex models (Boers et al., 1995, used for agricultural soils). For large-scale analyses, complex models are generally inappropriate because of the huge requirement for data, which are generally unavailable or associated with large uncertainties. Therefore, the use of simpler models with a smaller data demand is justified on a large spatial scale (De Vries et al., 1998; Kros, 2002). Statistical methods have the disadvantage that they are generally unable to generate future predictions; however, they are suitable for generation of the actual geographical distribution of solute concentrations or leaching fluxes. Process-oriented dynamic models, however, have been developed mainly to analyse temporal trends, either for a point application or an application in a spatial context. Typically, they do suffer from a high dependency on scarce observations.

In this research, results from two simple dynamic models, of different degrees of complexity, are compared with $\mathrm{NO}_{3}$ concentrations based on statistically scaled-up measurements in Dutch forest soils. This indicates the reliability of national scale assessment of $\mathrm{NO}_{3}$ concentrations below the root zone. The implications of the results with respect to critical $\mathrm{N}$ loads are also discussed.

\section{Methodology}

GENERAL

Three methods for the quantification of soil water $\mathrm{NO}_{3}$ concentrations below forest ecosystems in the Netherlands have been compared: (i) regression analysis based on observations and additional data on explanatory variables (Mol-Dijkstra and Kros, 1999), (ii) a semi-empirical model WANDA (Tietema, 2004), and (iii) a simple process oriented model SMART2 (Kros et al., 1995a). The results of the regression analysis were used as a reference, to quantify the performance of the two dynamic models, assuming that those results were the best estimate of the actual geographical distribution of the $\mathrm{NO}_{3}$ concentration.

The yearly average $\mathrm{NO}_{3}$ concentration at $1 \mathrm{~m}$ depth (i.e. below the root zone) has been investigated. A common feature of the three methods is that they are based on point information, i.e. either model-input data or observed concentrations. To derive a map of $\mathrm{NO}_{3}$ concentrations, the available point information was transformed to block values by taking the block median values of the underlying point values (Fig. 1). For each $250 \times 250 \mathrm{~m}^{2}$ grid cell one point value was determined, and these point values were

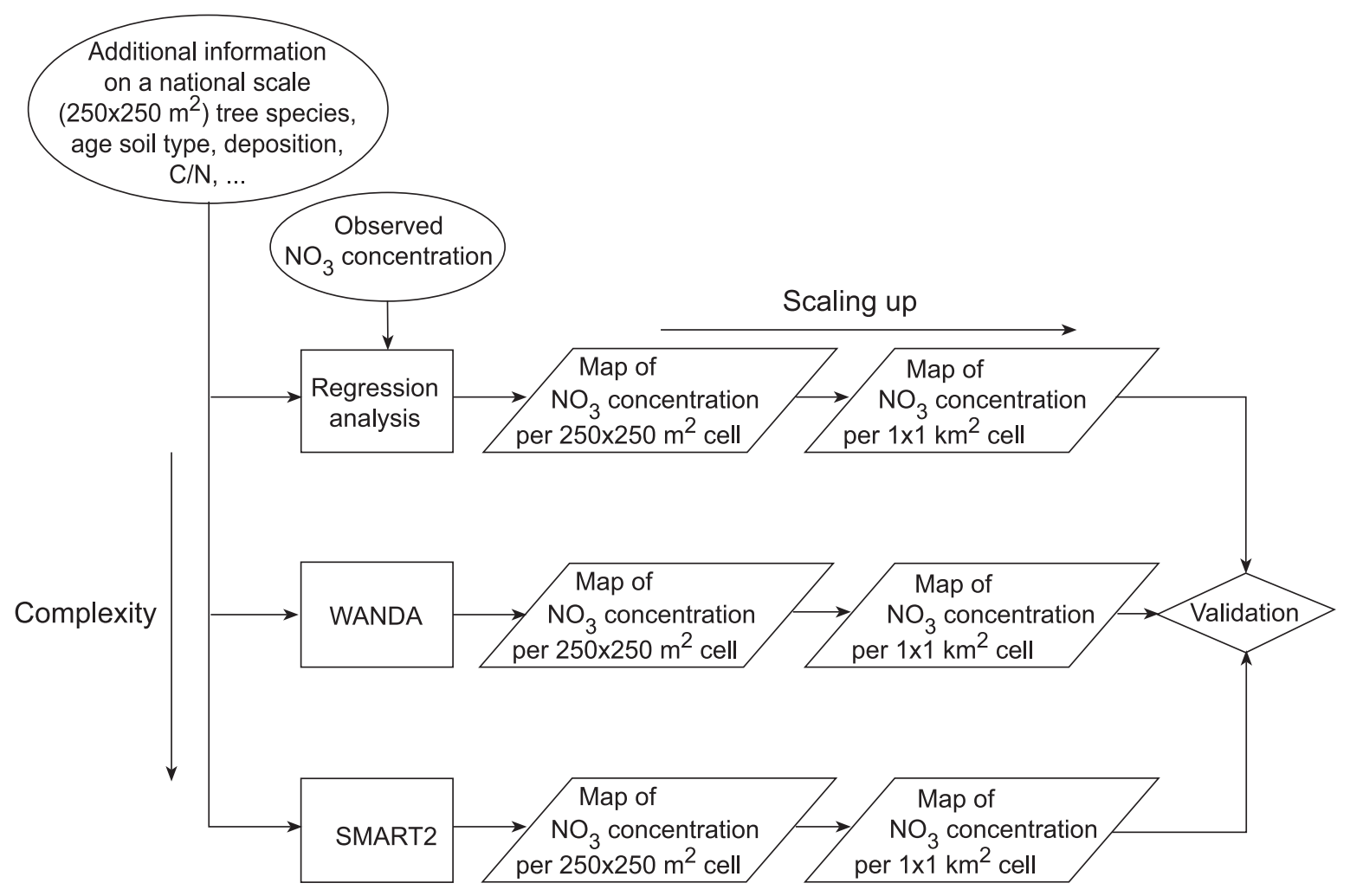

Fig. 1. Diagram showing the procedure of model validation and up-scaling 
aggregated into $1 \times 1 \mathrm{~km}^{2}$ blocks by taking the block median value of all the points within the block. A $1 \times 1 \mathrm{~km}^{2}$ grid was chosen as a reference, because deposition estimates were available at that scale.

\section{UP-SCALING POINT OBSERVATIONS BY REGRESSION ANALYSIS}

Regression analysis was applied to generate a map of soil solution $\mathrm{NO}_{3}$ concentrations on a $1 \times 1 \mathrm{~km}^{2}$ resolution grid (Mol-Dijkstra and Kros, 1999; Kros et al., 2002). This was achieved in two stages. Firstly, a multiple regression analysis at a $250 \times 250 \mathrm{~m}^{2}$ grid was used to estimate values at unsampled locations by including all relevant additional information which may account for systematic effects. Secondly, the $250 \times 250 \mathrm{~m}^{2}$ values were aggregated into a $1 \times 1 \mathrm{~km}^{2}$ grid (Fig. 1).

The regression analysis was based on a data set of 241 measurements on soil solution concentrations in forest stands on non-calcareous sandy soils throughout the Netherlands (De Vries et al., 1995b). The soil solution was sampled between February and May 1990. Composite samples, consisting of 20 sub-samples, were taken from the mineral top soil (0 to $30 \mathrm{~cm}$ ) and the mineral subsoil (60 to $100 \mathrm{~cm}$ ) in early spring. During this period, the composition of the soil solution corresponds reasonably with the flux weighted annual average soil solution concentration (De Vries et al., 1995b). Soil solution was extracted by centrifuging. The locations were restricted to non-calcareous soils throughout the country. The tree species included were Scotch pine (Pinus sylvestris), black pine (Pinus nigra), Douglas fir (Pseudotsuga menziessi), Norway spruce (Picea abies), Japanese larch (Larix leptolepis), oak (Quercus robur) and beech (Fagus sylvatica).

The sample sites were classified according to forest type classes, groundwater table classes and soil type. The tree species were classified as follows:

- Coniferous stands (Scotch pine), i.e. evergreen trees with moderate forest filtering capacity, growth rate and transpiration rate;

- Spruce stand (Douglas fir, Norway spruce and black pine), i.e. evergreen trees with high forest filtering capacity, growth rate and transpiration rate;

- Deciduous stands (Japanese larch, oak and beech), i.e. needle or leaf shedding trees with low forest filtering capacity, growth rate and transpiration rate.

All soil types were lumped into one class, i.e. noncalcareous sandy soils. A distinction was made into five groundwater table classes (Kros et al., 1995b) to distinguish soil wetness and drainage status.

For the regression analysis, candidate predictor variables were derived from available national databases and maps at a resolution of $250 \times 250 \mathrm{~m}^{2}$ (Mol-Dijkstra and Kros, 1999). These variables were: land-use, soil type, tree species, total deposition of $\mathrm{N}$ and $\mathrm{S}$, canopy closure, tree height, total area of the forest, nearest distance to the forest edge and the principal land-use at the nearest forest edge. These variables were selected because it was known from previous research (Leeters et al., 1994) that, potentially, they have a significant effect on the soil solution concentration and are available on a national scale. The soil solution concentrations were fitted to the candidate predictor variables, using multiple linear regression of GENSTAT (Genstat 5 Committee, 1987). Since the predictor variables are either quantitative (e.g. deposition) or qualitative (e.g. tree type) the regression equations include both types of variables. The models with the best fit were derived by the following procedure: (i) find the best model with the SELECT option (this option provides the set of predictor variables that delivers the best model) from GENSTAT, (ii) investigate whether non-linearity leads to improvements, by using the sPLINE option from GENSTAT (when the model with a spline fits better, the considered predictor variable was included with the derived spline) (iii) investigate whether the inclusions of interactions (a product of two or more predictor variables) leads to a better model. To meet the prerequisite of a normal distribution, the $\mathrm{NO}_{3}$ concentrations were log-transformed using the natural logarithm. For presentation, the results were back-transformed to a linear scale.

Stepwise selection process showed that significant predictive variables for the $\log _{\mathrm{e}} \mathrm{NO}_{3}$ concentration included (i) soil type (soil), (ii) tree species (veg), (iii) deposition of $\mathrm{NH}_{\mathrm{x}}$ $\left(\mathrm{NH}_{\mathrm{x} \text { dep }}\right)$, (iv) mean spring water table depth (MSW), (v) area of contiguous forest (area) and (vi) tree height. The inclusion of non-linear relationships (for MSW and area) resulted in a loss of significance for tree height. No significant interactions were discovered. Finally, the following multiple regression equation was derived for the $\mathrm{NO}_{3}$ concentration at depths of $60-100 \mathrm{~cm}$ :

$$
\begin{array}{r}
\log _{e} c \mathrm{NO}_{3}=\operatorname{soil}(i)+\operatorname{veg}(j)+0.33 \mathrm{NH}_{x \cdot d e p}-5.5 \cdot 0.025^{\text {MSW }} \\
-1.24 \text { area }^{0.24}-0.1
\end{array}
$$

where $\mathrm{cNO}_{3}$ is the $\mathrm{NO}_{3}$ concentration in $\mathrm{mol}_{\mathrm{c}} \mathrm{m}^{-3}$, soil(i) and $\operatorname{veg}(j)$ are constants that differ per soil type $\mathrm{i}$ and vegetation type $\mathrm{j}, \mathrm{NH}_{x \text { dep }}$ is the ammonium deposition in $\mathrm{kmol}_{\mathrm{c}} \mathrm{ha}^{-1} \mathrm{yr}^{-1}, M S W$ is the mean spring water table depth 
in $m$ below the soil surface and area is the area of connected forest in ha. The percentage of variance accounted for was 48\%. See Mol-Dijkstra and Kros (1999) for more details.

THE WANDA MODEL

WANDA (regional model With Aggregated Nitrogen DynAmics) is a semi-empirical process oriented model (Tietema, 2004) based on the predictive importance of the $\mathrm{C} / \mathrm{N}$ ratio for $\mathrm{NO}_{3}$ leaching. The hypothesis is that the lower the $\mathrm{C} / \mathrm{N}$ ratio of a site, the higher the risk of $\mathrm{NO}_{3}$ leaching. A negative correlation between both parameters has been found in various large data sets (McNulty et al., 1991; Gundersen, 1995; Tietema and Beier, 1995; Gundersen et al., 1998). WANDA consists of three organic nitrogen pools: trees, labile organic matter (LOM) and refractory organic matter (ROM) and two inorganic nitrogen pools, $\mathrm{NH}_{4}$ and $\mathrm{NO}_{3}$. The sources of inorganic nitrogen are atmospheric deposition and mineralisation of ROM. The sinks are plant uptake, microbial immobilisation in $\mathrm{LOM}$ and $\mathrm{NO}_{3}$ leaching. Net plant uptake and ROM mineralisation are negative linear functions of tree age. Beyond a threshold tree age, there is neither plant uptake nor ROM mineralisation. Microbial immobilisation is a function of the $\mathrm{C} / \mathrm{N}$ ratio of the organic layer. Below a certain critical $\mathrm{C} / \mathrm{N}$ ratio, no inorganic nitrogen is immobilised; beyond a maximal feasible $\mathrm{C} / \mathrm{N}$ ratio, all available inorganic nitrogen is immobilised. Between these two values, the fraction taken up varies linearly with $\mathrm{C} / \mathrm{N}$.

The net uptake of $\mathrm{NH}_{4}$ and $\mathrm{NO}_{3}$ in the various pools is calculated in the following sequence. $\mathrm{NH}_{4}$ is taken up preferentially over $\mathrm{NO}_{3}$ by both plants and microbes; before the $\mathrm{NO}_{3}$ becomes available for microbial uptake, the tree uptake must be satisfied. The $\mathrm{NH}_{4}$ and $\mathrm{NO}_{3}$ in excess of the demand are leached as $\mathrm{NO}_{3}$, assuming complete nitrification and no denitrification. This assumption limits the use of WANDA to well-drained soils.

There are only five unknown parameters in this relatively simple model, the four threshold $\mathrm{C} / \mathrm{N}$ ratios for microbial immobilisation in LOM (upper and lower limit for $\mathrm{NH}_{4}$ and $\mathrm{NO}_{3}$ immobilisation) and the maximum rate of ROM mineralisation at a theoretical tree age of zero. All other parameters can be derived from available forestry information. The five unknown parameters were optimised using the relationship between $\mathrm{C} / \mathrm{N}$ ratio in the organic layer and $\mathrm{NO}_{3}$ leaching found by Gundersen (1995) in the ECOFEE (Element Cycling and Output-fluxes in Forest Ecosystems in Europe) data set. WANDA calculates $\mathrm{NO}_{3}$ leaching directly. To calculate $\mathrm{NO}_{3}$ concentrations in drainage water, the drainage water flux is calculated as a function of tree species and age.
THE SMart2 MODEL

SMART2 (an extended version of Simulation Model for Acidification's Regional Trends) is a simple onecompartment soil acidification and nutrient cycling model that includes the major hydrological and biogeochemical processes in the vegetation, litter and mineral soil (Kros et al., 1995b). Apart from nitrate $\left(\mathrm{NO}_{3}\right)$ and ammonium $\left(\mathrm{NH}_{4}\right)$ concentrations, the model predicts changes in the soil solution of aluminium ( $\mathrm{Al}$ ), base cations (BC), sulphate $\left(\mathrm{SO}_{4}\right)$ and $\mathrm{pH}$, and the solid phase characteristics depicting the acidification status, i.e. carbonate content, base saturation and readily available Al content. The SMART2 model is an extension of the dynamic soil acidification model SMART (De Vries et al., 1989); it includes a nutrient cycle and an improved modelling of hydrology. The SMART2 model consists of a set of mass balance equations, describing the soil input-output relationships, and a set of equations describing the rate-limited and equilibrium soil processes. The soil solution chemistry in SMART2 depends solely on the net element input from the atmosphere (the product of deposition and filtering factor) and groundwater (seepage), canopy interactions (foliar uptake, foliar exudation), geochemical interactions in the soil $\left(\mathrm{CO}_{2}\right.$ equilibria, weathering of carbonates, silicates and/or Al-hydroxides, $\mathrm{SO}_{4}$ sorption and cation exchange) and a complete nutrient cycle (litterfall, mineralisation, root uptake, nitrification and denitrification). The adsorption of $\mathrm{NH}_{4}$ is not taken into account.

Growth of the vegetation and litterfall are modelled by a logistic growth function, acting as a forcing function. Nutrient uptake is limited only when there is a shortage in the soil solution. Litterfall and root decay is the input to an organic pool containing $\mathrm{N}$, divalent base cations $(\mathrm{BC} 2$, i.e. $\mathrm{Mg}+\mathrm{Ca}$ ) and $\mathrm{K}$. In assessing mineralisation of above-ground organic matter (litter, including dead roots in the litter layer), a distinction is made between a rapidly decomposing pool of fresh litter (less than one year old) and a slowly decomposing pool of old litter (over a year old). Nitrification and denitrification in the entire soil layer are described as a fraction of the net input. The mineralisation, nitrification and denitrification rate constants are influenced by the mean spring water table and $\mathrm{pH}$.

Soil-solute transfers are described by simple rate-limiting (zero-order) reactions (e.g. uptake and silicate weathering) or by equilibrium reactions (e.g. carbonate and Al-hydroxide weathering and cation exchange). The influences of environmental factors such as $\mathrm{pH}$ on rate-limiting reactions and rate-limitation of weathering and exchange reactions are not simulated. Solute transport is described by assuming complete mixing of the elemental input within one 
homogeneous soil compartment with a constant density and a fixed depth (at least the root zone). Since SMART2 is a single layer soil model which neglects vertical heterogeneity, it predicts the concentration of the soil water leaving the root zone. The annual water flux percolating from this layer is taken as equal to the annual precipitation minus the annual evapotranspiration for the soil depth considered. Both terms must be specified in model input. The time step of the model is one year; therefore, seasonal variations are not considered.

\section{NATIONAL SCALE APPLICATION AND MODEL COMPARISON}

Input data for national scale applications of WANDA and SMART2 were divided into system inputs and initial values of variables and parameters. System inputs for both models are the atmospheric deposition, hydrology and vegetation development or tree age. Input data included (i) a specific deposition scenario for each grid cell, (ii) model variables and parameters which were either related to a soil or vegetation type or a combination of both and (iii) a soil map and vegetation map relating variables and parameters to grid cells. For the national scale application, two $250 \times$ $250 \mathrm{~m}^{2}$ grids were made, one representing the dominant soil type and the other the dominant vegetation type. In these maps, seven soil classes and four vegetation types were distinguished. Because of the assumption regarding nitrification and denitrification in the WANDA model, this study was confined to forest on sandy soils. Therefore, only one soil type (non-calcareous sandy soils) and three vegetation types (coniferous, spruce and deciduous) were used. This comprises $80 \%$ of the 350000 ha total forest area in The Netherlands, roughly $10 \%$ of the surface area of the country.

An essential system input for WANDA is the $\mathrm{C} / \mathrm{N}$ ratio of the organic layer. This ratio was calculated for each grid by a multiple regression relation based on measured $\mathrm{C} / \mathrm{N}$ ratios in the forest floor and additional data. For this relation, the same dataset (i.e. De Vries et al., 1995b) was used as for the derivation of the $\mathrm{NO}_{3}$ concentration map, which also includes solid phase analyses. The multiple regression relation derived $\left(\mathrm{R}^{2}=0.44\right)$ contained as significant predictor variables, in decreasing order of importance: tree-species, soil type and age of the trees.

It is important to realise that WANDA and SMART 2 simulate values averaged yearly, whereas the data set represents the soil water $\mathrm{NO}_{3}$ concentration in early spring (February to May). This influences the quality of the validation. This dataset however, is the only nationwide set on soil solution concentrations below forest in The Netherlands.

\section{Results and discussion}

\section{COMPARISON OF MAPS}

The upscaled spatial distribution as calculated by the three methods is given in Fig. 2a-c. On these maps, all $1 \mathrm{~km}$ cells that contain forest are shown. The three methods show different results. Compared to the regression, SMART2 calculates, for the Veluwe area, i.e. a forested area in the centre of the country, rather high $\mathrm{NO}_{3}$ concentrations whereas WANDA simulates rather low concentrations. This difference was caused mainly by the way forest filtering is incorporated in WANDA and SMART2. Both the regression model and WANDA account explicitly for the total area of the forest, assuming that a larger continuous area of dense forests results in lower forest filtering and, thus, a lower input of atmospheric deposition (Draaijers and Erisman, 1993). The SMART2 model, however, includes only forest filtering factors that depend on forest type, independent of the forested area. These factors were large for spruce and small deciduous forest. Taking into account that the Veluwe is densely forested with spruce, it is obvious why WANDA and the regression model calculate lower $\mathrm{NO}_{3}$ concentration for this area. Another difference between WANDA and SMART2, is that WANDA calculates clearly higher $\mathrm{NO}_{3}$ concentrations for wet soil conditions. This can be seen in Fig. 2c where, in lowlands (Gelderse Valley) in the middle of the country and in the brook valleys in the southern part of the country, WANDA also calculates higher $\mathrm{NO}_{3}$ concentrations than the regression model. The average $\mathrm{NO}_{3}$ concentration for wet sandy soils (i.e. a mean spring groundwater table of less than $25 \mathrm{~cm}$ below the surface) calculated by the regression model and SMART 2 were 4 and $5 \mathrm{mg} \mathrm{NO} \mathrm{I}^{-1}$ respectively, whereas WANDA calculated 19 mg NO${ }_{3}{ }^{-1}$. This result is an artefact of WANDA, which does not include denitrification.

When the spatial distributions for each method are inspected separately and the above-mentioned omissions are disregarded, the spatial images are rather consistent, i.e. high $\mathrm{NO}_{3}$ concentration in areas with high deposition and vice versa.

\section{COMPARISON OF CUMULATIVE DISTRIBUTION FUNCTIONS}

When the results are compared as cumulative distribution functions (CDF), the differences between the three methods appear much smaller. Figure 3 a shows the corresponding results for the maps shown in Fig. 2, i.e. a CDF of all $1 \times 1$ $\mathrm{km}^{2}$ grid cell values. From this figure, it is obvious that at high concentrations $\left(>30 \mathrm{mg} \mathrm{NO}_{3} \mathrm{l}^{-1}\right)$ both WANDA and SMART2 over-estimated the $\mathrm{NO}_{3}$ concentrations. At lower 

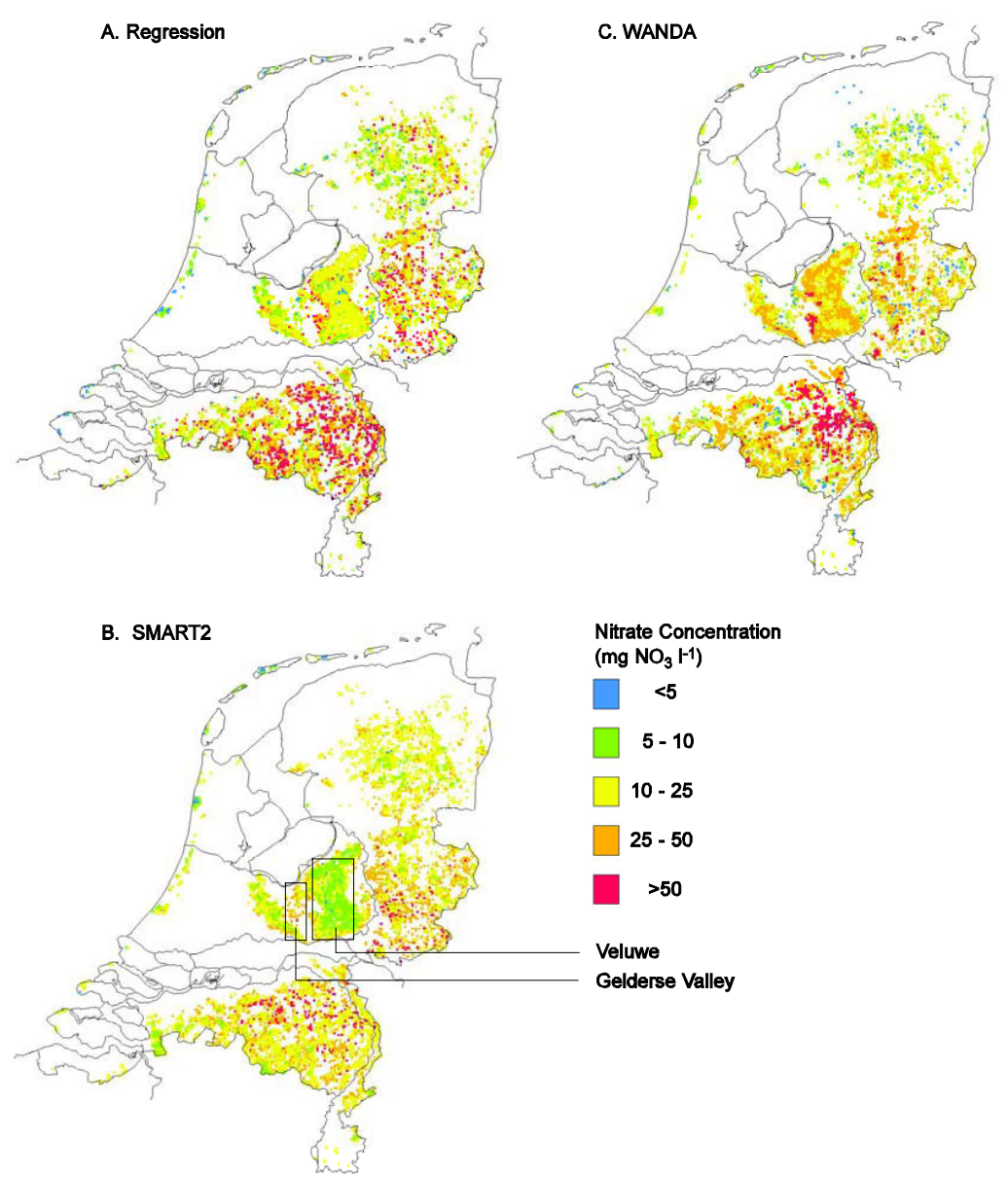

Fig. 2. Maps of the upscaled $\mathrm{NO}_{3}$ concentration for all $1 \mathrm{~km}$ cells that contain forest as estimated by the regression model (a) and the dynamic models WANDA (b) and SMART2 (c), The white cells do not contain forest.

concentrations ( $\left.<30 \mathrm{mg} \mathrm{NO}_{3} 1^{-}\right)$, SMART2 under-estimated and WANDA over-estimated the $\mathrm{NO}_{3}$ concentrations, while WANDA under-estimated at concentrations below 0.10 mg NO $1_{3} 1^{-1}$.

To investigate the role of spatial scale in the performance of the models, results of both models as well as the regression data, were aggregated into larger cell sizes, i.e. 5, 10, 15, 20 and $25 \mathrm{~km}^{2}$. Figure 3 shows that the models perform best on a $5 \mathrm{~km}^{2}$ grid and worst at a $25 \mathrm{~km}^{2}$ grid. This effect is confirmed only in part in terms of the calculated mean squared error of prediction (MSEP) (Table 1). because a larger grid size improves the performance of both models. Although the performance increases in terms of the MSEP, the spatial resolution, of course, decreases. Consequently, there is a gain in reliability (loss in uncertainty) at the cost of spatial variability. This trade-off between spatial resolution and uncertainty has been reported previously, see e.g. Heuvelink and Pebesma (1999) and Pebesma et al.

Table 1. Mean squared error of prediction (MSEP) $)^{1)}$ between WANDA results and the regression data and SMART2 results and regression data for five grid sizes

\begin{tabular}{lllllll}
\hline Model & $1 \times 1 \mathrm{~km}^{2}$ & $5 \times 5 \mathrm{~km}^{2}$ & $10 \times 10 \mathrm{~km}^{2}$ & $15 \times 15 \mathrm{~km}^{2}$ & $20 \times 20 \mathrm{~km}^{2}$ & $25 \times 25 \mathrm{~km}^{2}$ \\
\hline WANDA & 0.49 & 0.30 & 0.25 & 0.18 & 0.18 & 0.19 \\
SMART2 & 0.43 & 0.24 & 0.20 & 0.15 & 0.15 & 0.14 \\
\hline
\end{tabular}

1) $M S E P=\frac{1}{N} \sum_{i}^{N}\left(P_{i}^{(1)}-P_{i}^{(2)}\right)^{2}$ 


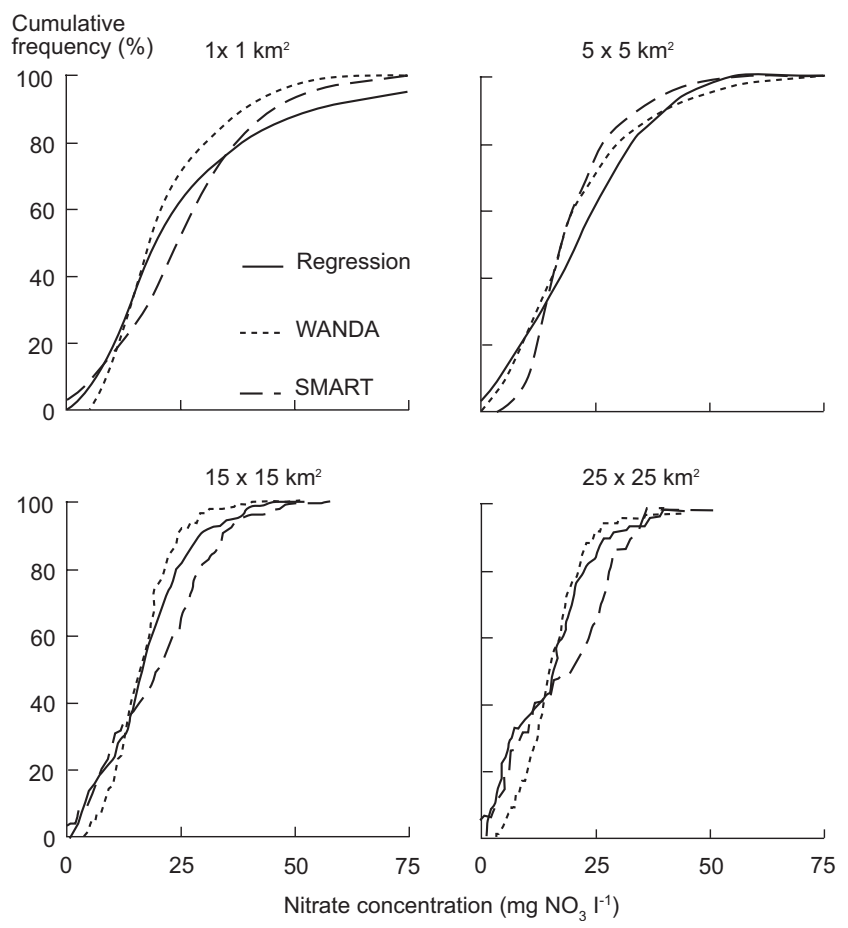

Fig. 3. Cumulative distribution functions for a $1 \times 1 \mathrm{~km}^{2}, 5 \times 5 \mathrm{~km}^{2}$, $15 \times 15 \mathrm{~km}^{2}$ and a $25 \times 25 \mathrm{~km}^{2}$ grid of the calculated $\mathrm{NO}_{3}$ concentration by regression, WANDA and SMART 2

(2000). An important consequence of the loss of detail, i.e. averaging out of extremes, is a decreased capability to identify areas where a concentration standard is exceeded. It is, however, unwise to draw conclusions on spatially explicit model results based only on CDFs, because large regional differences can exist, even at rather small distances (0.5-1 km).

\section{IMPACTS OF THE METHOD USED ON THE}

\section{EXCEEDANCE OF GROUNDWATER STANDARDS FOR NITRATE}

Comparison with the EU groundwater standard for phreatic groundwater for $\mathrm{NO}_{3}$ of $50 \mathrm{mg} \mathrm{l}^{-1}\left(0.8 \mathrm{~mol}_{\mathrm{c}} \mathrm{m}^{-3}\right)$ shows that all three methods indicate substantial areas where this standard has been exceeded. For a $1 \times 1 \mathrm{~km}^{2}$ grid, this area ranges from 10 to $20 \%$ of the area considered depending on the method used (Fig. 3a). These areas are located mainly in the south-eastern part of the country, which corresponds to areas with high $\mathrm{NH}_{3}$ emission and deposition due to intensive animal husbandry. In addition, all three methods show large areas, ranging from 40 to $80 \%$ of the total area considered, where the guidance concentration $(25 \mathrm{mg} \mathrm{NO}$ $\mathrm{l}^{-1} ; 0.4 \mathrm{~mol}_{\mathrm{c}} \mathrm{m}^{-3}$ ) has been exceeded (see Fig. 3a, where starting from the horizontal axis at $25 \mathrm{mg} \mathrm{l}^{-1}$ the lowest and the highest values can be found). Note that this range is much wider than that where the groundwater standard is exceeded. This because $25 \mathrm{mg} \mathrm{NO} \mathrm{l}^{-1}$ lies around the median values, whereas $50 \mathrm{mg} \mathrm{NO}_{3} \mathrm{l}^{-1}$ lies in the tail of the distribution. In other words, the uncertainty in exceedance area is larger for the guidance concentration than for the EU standard.

Note also that the exceedance area is very dependent on the grid size used. The larger the grid size, the smaller the exceedance area. However, the method used here is inappropriate for deriving the exceedance area. The correct way is to start at the point scale data for a $250 \times 250 \mathrm{~m}^{2}$ grid and count the number of $250 \times 250 \mathrm{~m}^{2}$ cells within a $1 \mathrm{~km}^{2}$ with a concentration higher than the standard concentration (Kros et al., 1999).

\section{RELATION WITH CRITICAL LOADS}

The results of spatial distribution of $\mathrm{NO}_{3}$ concentrations below the root zone of semi-natural ecosystems are of special interest in respect of the exceedance of critical concentrations. Because critical loads are calculated by a steady-state method, they do take into account changes in $\mathrm{N}$ (im)mobilisation from the soil and litter layer. In reality,

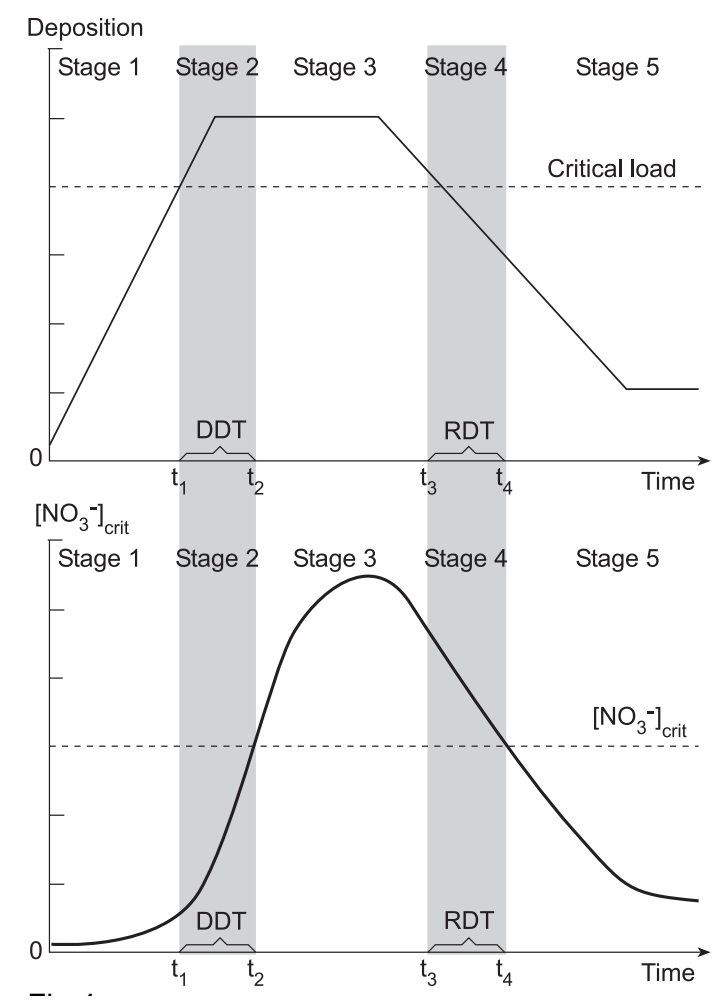

Fig. 4. A typical temporal evolution of the deposition (top) and a soil chemical variable (e.g. $\mathrm{NO}_{3}$ concentration) (bottom). The delay between the (non-) exceedance of the critical load and the (non) violation of the critical chemical criterion: Damage Delay Time (DDT) and Recovery Delay Time (RDT) (After: Posch and Hettelingh, 2001) 
however, dynamic processes also play an important role in the context of critical loads (Tietema et al., 2002), especially, in the short-term $(<50$ years $)$.

Posch and Hettelingh (2001) address the relation between dynamics and critical load (Fig. 4). During Stage 1, the deposition is above the critical load but the chemical variable is still below the critical value. Therefore, at this stage, violation of the criterion does not occur despite the exceedance of the critical load (Damage Delay Time = $\left.t_{2}-t_{1}\right)$. During Stage 4, the deposition is below the critical load, but the criterion is still exceeded (Recovery Delay Time $=t_{4}-t_{3}$ ), because of mobilisation of accumulated $\mathrm{N}$.

To quantify the difference between the $\mathrm{NO}_{3}$ concentrations calculated using the dynamic models SMART2 and WANDA on the one hand and a steady state method on the other hand, the potential $\mathrm{NO}_{3}$ concentration was calculated neglecting all dynamic aspects. The steady state $\mathrm{NO}_{3}$ concentration (in $\mathrm{mol}_{\mathrm{c}} \mathrm{m}^{-3}$ ) was (see De Vries et al., 1994):

$$
\mathrm{cNO}_{3}=\frac{N_{d e p}-N_{u p}-N_{d e}}{P E}
$$

where $\mathrm{CNO}_{3}$ is the $\mathrm{NO}_{3}$ concentration in $\mathrm{mol}_{\mathrm{c}} \mathrm{m}^{-3}, N_{\text {dep }}$ is the $\mathrm{N}$ deposition ( $\left.\mathrm{mol}_{\mathrm{c}} \mathrm{m}^{-2} \mathrm{yr}^{-1}\right), N_{u p}$ is net long-term $\mathrm{N}$ uptake $\left(\mathrm{mol}_{\mathrm{c}} \mathrm{m}^{-2} \mathrm{a}^{-1}\right), N_{d e}$ the denitrification $\left(\mathrm{mol}_{\mathrm{c}} \mathrm{m}^{-2} \mathrm{yr}^{-1}\right)$, and $P E$ the precipitation excess ( $\left.\mathrm{m} \mathrm{yr}-^{-1}\right)$.

Figure 5 shows that the steady-state $\mathrm{NO}_{3}$ concentration is usually much higher than the actual concentration, indicating that a lot of $\mathrm{N}$ is still being immobilised (either in the soil or in the vegetation) in forest ecosystems in the Netherlands, assuming that other sinks such as re-emission of ammonia and leaching of organic nitrogen are negligible. All three methods provide a consistent result, despite some

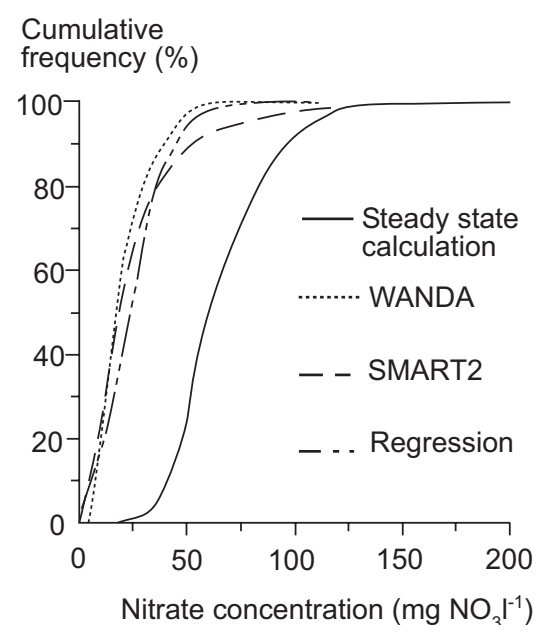

Fig. 5. Cumulative distribution functions of the calculated $\mathrm{NO}_{3}$ concentration as calculated with a steady state methods with deposition for 1990 and the $\mathrm{NO}_{3}$ concentration as calculated with the three methods at a $1 \times 1 \mathrm{~km}^{2}$ grid differences, especially at higher $\left(>25 \mathrm{mg} \mathrm{NO} \mathrm{l}^{-1}\right)$ concentrations.

To assess the short-term and long-term effects in terms of deposition, the data were compared with recently updated critical loads for the Netherlands (De Vries et al., 2000). Model results were selected from those sites where the $\mathrm{NO}_{3}$ concentration was between $25 \pm 0.56 \mathrm{mg} \mathrm{l}^{-1}$ and $50 \pm 0.56$ $\mathrm{mg} \mathrm{l}^{-1}$. The window of $\pm 0.56 \mathrm{mg} \mathrm{l}^{-1}\left( \pm 0.04 \mathrm{~mol} \mathrm{~m}_{\mathrm{c}}^{-3}\right)$ was determined empirically, such that the window size does not affect the distribution; for a wider window the shape of the CDFs changes, whereas for a smaller window the CDFs became less smooth. These results together with the critical $\mathrm{N}$ load derived for critical $\mathrm{NO}_{3}$ concentrations of 25 and 50 $\mathrm{mg} \mathrm{l}^{-1}$ are given in Fig. 6, which also shows that the actual situation is far from steady state. For all three methods and both criteria, the forest soils can accept nitrogen deposition loads higher than the long-term critical loads without exceeding the critical concentrations. This means that many semi-natural terrestrial ecosystems in the Netherlands are immobilising $\mathrm{N}$ under present conditions. Also, in this situation, all three methods provide comparable results. However, when most systems attain a steady-state with respect to nitrogen saturation, the situation will become serious. Around $80 \%$ of the area is at risk of exceeding the EU standard of $50 \mathrm{mg} \mathrm{NO}_{3} \mathrm{l}^{-1}$ (Fig. 5). Steady-state seems to have been reached in about $10 \%$ of the area according to the up-scaled monitoring data (regression) for the $50 \mathrm{mg}^{-1}$ criterion. That the models WANDA and SMART2 do not reach the same conclusion, indicates that they overestimate the capability to store $\mathrm{N}$ in the ecosystem in particular cases.

\section{Conclusions}

The soil water $\mathrm{NO}_{3}$ concentration maps calculated by the three methods provided results which were clearly different. Yet the spatial distributions in the form of a cumulative distribution function provided comparable results, especially at $5 \times 5 \mathrm{~km}^{2}$ grid. As the grid cell size increases, the spatial resolution decreases as does the ability to determine the specific area where the soil $\mathrm{NO}_{3}$ concentration exceeds the EU limit.

The differences between the three approaches are caused mainly by the differences in handling forest filtering and denitrification. To improve predictions for densely forested areas, the SMART2 model must be extended with a spatial dependent filtering factor, i.e. distance to the nearest forest edge, while the predictions of WANDA under wet soil conditions, can be improved by incorporating denitrification. All results point to the fact that most forests in the Netherlands are still accumulating $\mathrm{N}$ and the actual situation is still far from steady state. At high atmospheric $\mathrm{N}$ input 




Fig. 6. Percentage protected area as a function of the total $N$ deposition according to a steady-state calculation and the three inspected methods at the target value on $\mathrm{NO}_{3}$ of $25 \mathrm{mg} \mathrm{l}^{-1}$ (a) and the EU standard on $\mathrm{NO}_{3}$ of $50 \mathrm{mg} \mathrm{l}^{-1}$ (b)

$\left(>4000 \mathrm{~mol} \mathrm{ha}_{\mathrm{c}}^{-1} \mathrm{yr}^{-1}\right)$, all three methods indicate that the EU standard for phreatic groundwater for $\mathrm{NO}_{3}\left(50 \mathrm{mg} \mathrm{l}^{-1}\right)$ is already exceeded. These dynamic models are useful for quantifying the gap between the actual $\mathrm{NO}_{3}$ leaching and the potential $\mathrm{NO}_{3}$ leaching of a steady state. For this goal, the models provide a consistent result.

\section{Acknowledgement}

This work was funded by the Dutch National Programme on Nitrogen and the Ministry of Agriculture, Nature and Fisheries. Jan-Cees Voogd kindly assisted with data handling and statistical calculations.

\section{References}

Bobbink, R., Hornung, M. and Roelofs, J.G.M., 1998. The effects of air-borne nitrogen pollutants on species diversity in natural and semi-natural European vegetation. J. Ecol., 86, 717-738.

Boers, P.C.M., Finke, P.A., van Grinsven, J.J.M. and Groenendijk, P., 1995. Definition and feasibility of a model for the calculation of nutrient emission to groundwater and surface water, a cooperration between three institutes. RIZA werkdocument 96.081 X. Lelystad. 55pp.

Boxman, A.W. and van Dijk, H.F.G., 1988. Het effect van landbouw ammonium deposities op bos- en heidevegetaties. Katholieke Universiteit Nijmegen. 96pp.

De Vries, W., 1994. Soil response to acid deposition at different regional scales; Field and laboratory data, critical loads and model predictions. Wageningen University, Wageningen, The Netherlands. 487pp.

De Vries, W., Posch, M. and Kämäri, J., 1989. Simulation of the long-term soil response to acid deposition in various buffer ranges. Water Air Soil Pollut., 48, 349-390.

De Vries, W., Reinds, G.J. and Posch, M., 1994. Assessment of critical loads and their exceedance on European forests using a one-layer steady-state model. Water Air Soil Pollut., 72, 357394.
De Vries, W., van Grinsven, J.J.M., van Breemen, N., Leeters, E.E.J.M. and Jansen, P.C., 1995a. Impacts of acid deposition on concentrations and fluxes of solutes in acid sandy forest soils in the Netherlands. Geoderma, 67, 17-43.

De Vries, W., Kros, J. and van der Salm, C., 1995b. Modelling the impact of acid deposition and nutrient cycling on forest soils. Ecol. Model., 79, 231-254.

De Vries, W., Kros, J., van der Salm, C., Groenenberg, J.E. and Reinds, G.J., 1998. The use of upscaling procedures in the application of soil acidification models at different spatial scales. Nutr. Cycl. Agroecosyst., 50, 223-236.

De Vries, W., van der Salm, C., van Hinsberg, A. and Kros, J., 2000. Gebiedsspecifieke, kritische depositieniveaus voor stikstof en zuur voor terrestrische ecosystemen. Milieu, 144158 .

Dise, N.B., Matzner, E. and Gundersen, P., 1998. Synthesis of Nitrogen Pools and Fluxes from European Forest Ecosystems. Water Air Soil Pollut., 105, 143-154.

Draaijers, G.P.J. and Erisman, J.W., 1993. Atmospheric sulphur deposition to forest stands: throughfall estimates compared to estimates from inference. Atmos. Environ. A, 27, 43-55.

Genstat 5 Committee, 1987. Reference Manual. Clarendon Press, Oxford, UK.

Gundersen, P., 1995. Nitrogen deposition and leaching in European forests - preliminary results from a data compilation. Water Air Soil Pollut., 85, 1179-1184.

Gundersen, P., Emmet, B.A., Kjønaas, O.J., Koopmans, C. and Tietema, A., 1998. Impact of nitrogen deposition on nitrogen cycling in forests: a synthesis of NITREX data. Forest Ecol. Manage., 101, 37-55.

Heuvelink, G.B.M. and Pebesma, E.J., 1999. Spatial aggregation and soil process modelling. Geoderma, 89, 47-65.

Kros, J., 2002. Evaluation of biogeochemical models at local and regional scale. Wageningen University, Wageningen, The Netherlands. 284pp.

Kros, J., Mol Dijkstra, J.P. and Pebesma, E.J., 2002. Assessment of the prediction error in a large-scale application of a dynamic soil acidification model. Stoch. Environ. Res. Risk Assessment, 16, 279-306.

Kros, J., Pebesma, E.J., Reinds, G.J. and Finke, P.A., 1999. Uncertainty assessment in modelling soil acidification at the European scale: a case study. J. Environ. Qual., 28, 366-377. 
Kros, J., Reinds, G.J., de Vries, W., Latour, J.B. and Bollen, M.J.S., 1995a. Modelling the response of terrestrial ecosystems to acidification and desiccation scenarios. Water Air Soil Pollut., 85, 1101-1106.

Kros, J., Reinds, G.J., de Vries, W., Latour, J.B. and Bollen, M.J.S., 1995b. Modelling of soil acidity and nitrogen availability in natural ecosystems in response to changes in acid deposition and hydrology. SC-DLO Report 95. Wageningen, The Netherlands. 90pp.

Leeters, E.E.J.M., Hartholt, H., de Vries, W. and Boumans, L.J.M., 1994. Effects of acid deposition on 150 forest stands in the Netherlands. 4. Relationships between deposition level, stand and site characteristics and the chemical composition of needles, mineral soil, soil solution and groundwater. Report 69.4. DLO Winand Staring Centre, Wageningen, The Netherlands.

McNulty, S.G., Aber, J.D. and Boone, R.D., 1991. Spatial changes in forest floor and foliar chemistry of spruce-fir forests across New England. Biogeochem., 14, 13-29.

Mol-Dijkstra, J.P. and Kros, J., 1999. Calibration of the model SMART2 in the Netherlands, using data available at the European scale. SC-DLO report 162. Wageningen, The Netherlands.

Pebesma, E.J. and de Kwaadsteniet, J.W., 1997. Mapping groundwater quality in the Netherlands. J. Hydrol., 200, 364386.

Pebesma, E.J., Heuvelink, G.B.M. and Kros, J., 2000. Error assessment in a soil acidification modelling study: efficiency issues and change of support. In: Proceedings of Accuracy 2000, the 4th International Symposium on Spatial Accuracy Assessment in Natural Resources and Environmental Science. G.B.M. Heuvelink and M.J.P.M. Lemmens (Eds). Amsterdam, The Netherlands. 521-528.
Posch, M. and Hettelingh, J.P., 2001. From critical loads to dynamic modelling. In: Modelling and mapping of critical thresholds in Europe, Status report 2001 coordination center for effects, M. Posch, P.A.M. De Smet, J.P. Hettelingh and R.J. Dowing (Eds). RIVM, Bilthoven, The Netherlands.

Tietema, A., 2004. WANDA, a regional dynamic nitrogen model (With Aggregated Nitrogen DynAmics) for nitrate leaching from forests. Hydrol. Earth Syst. Sci., 8, 803-812.

Tietema, A. and Beier, C., 1995. A correlative evaluation of nitrogen cycling in the forest ecosystems of the EC projects NITREX and EXMAN. Forest Ecol. Manage., 71, 143-151.

Tietema, A., Mol Dijkstra, J.P. and Kros, J., 2002. Dynamic nitrogen deposition thresholds during forest stand developments in a Douglas fir forest analysed with two nitrogen models SMART2 and MERLIN. Hydrol. Earth Syst. Sci., 6, 375-382. Tiktak, A., Alkemade, J.R.M., van Grinsven, J.J.M. and Makaske, G.B., 1998. Modelling cadmium accumulation at a regional scale in the Netherlands. Nutr. Cycl. Agroecosyst., 50, 209-222.

Van Breemen, N., Burrough, P.A., Velthorst, E.J., van Dobben, H.F., de Wit, T., de Ridder, T.B. and Reynders, H.F.R., 1982. Soil acidification from atmospheric ammonium sulfate in forest canopy throughfall. Nature, 299, 548-550. 